\title{
INHOMOGENEOUS GRAIN COARSENING BEHAVIOR IN SUPERSOLVUS HEAT TREATED NICKEL-BASED SUPERALLOY RR1000
}

\author{
I.M.D. Parr ${ }^{1}$, T.J. Jackson ${ }^{1}$, M.C. Hardy ${ }^{1}$, D.J Child ${ }^{1}$, C. Argyrakis ${ }^{1}$, K. Severs ${ }^{2}$, V. Saraf ${ }^{2}$, J.M. Stumpf ${ }^{2}$ \\ ${ }^{1}$ Rolls-Royce plc, PO Box 31, Derby, DE24 8BJ, UK \\ ${ }^{2}$ ATI Forged Products, Cudahy, PO Box 8902, Cudahy, WI 53110, USA
}

Keywords: RR1000, Abnormal Grain Growth, Critical Grain Growth, Supersolvus Heat Treatment, Isothermal Forging

\begin{abstract}
RR1000 billet material has been isothermally forged using various nominal strain rate and temperature conditions. A supersolvus heat treatment has then been applied in order to assess the effect of local strain, strain rate and forging temperature on the extent of grain coarsening.

This work has found that a range of forging strain exists where inhomogeneous grain coarsening is promoted during slow heating through the $\gamma^{\prime}$ solvus temperature and results in excessively coarse final grain microstructures. Interrupted supersolvus heat treatments have shown that this process is caused by the inhibited and/or premature growth of certain grains relative to their neighbors. It has been found that excessive grain coarsening can be limited by increasing the applied forging strain rate, reducing the forging temperature or increasing the heating rate to the supersolvus heat treatment temperature.

This coarsening mechanism has been described as abnormal grain growth (AGG), primarily occurring at low applied forging strain rates in the fully superplastic forging regime. It is thought to be distinct from critical grain growth (CGG) coarsening behavior which is typically related to higher applied forging strain rates where superplastic deformation is limited.
\end{abstract}

\section{Introduction}

Today's large civil gas turbine engines rely on nickel-based superalloy components with highly tailored microstructures. One such alloy is RR1000, which is produced by a powder metallurgy route. It is a high strength alloy with a homogeneous $\gamma / \gamma^{\prime}$ microstructure and a $\gamma^{\prime}$ solvus temperature of $1149{ }^{\circ} \mathrm{C}$ [1], although dissolution of the primary $\gamma^{\prime}$ particles will begin at around $1135{ }^{\circ} \mathrm{C}$. RR1000 is used for critical rotating parts in the jet engine such as the high pressure turbine (HPT) disc.

RR1000 alloy is produced by argon gas atomization to create a spherical powder particle. This is then sieved, hot isostatically pressed and hot extruded to create billet material. The billet is isothermally forged below the $\gamma^{\prime}$ solvus to generate a forging with a homogeneous fine-grained microstructure consisting of $\gamma$ grains with primary $\gamma^{\prime}$ precipitates on the grain boundaries.

The forging will then be given a solution heat treatment which may be above or below the $\gamma^{\prime}$ solvus temperature. A sub-solvus heat treatment produces a fine grained microstructure (approximately $7 \mu \mathrm{m}$, ASTM 11.5) of $\gamma$ grains with coherent and incoherent primary $\gamma^{\prime}$ mostly on the grain boundaries. The sizes of coherent secondary and tertiary $\gamma^{\prime}$ precipitates, which form within the $\gamma$ grains, are determined by the cooling rate and ageing parameters respectively. The fine grained variant of RR1000 has a high yield and ultimate strength and high fatigue strength especially at temperatures $<650{ }^{\circ} \mathrm{C}$ [2]. A supersolvus heat treatment dissolves the primary $\gamma^{\prime}$ particles and results in a coarse grained microstructure (approximately $30 \mu \mathrm{m}$, ASTM 7). After controlled cooling and aging the microstructure consists of equiaxed $\gamma$ grains that contain only secondary and tertiary $\gamma^{\prime}$ precipitates. Coarse Grain RR1000 has slower dwell crack growth rates and improved creep resistance, but reduced tensile strength and reduced fatigue strength at temperatures $<650{ }^{\circ} \mathrm{C}[2]$.

The balance of properties from the coarse grain variant is attractive for many applications, but achieving the intended grain size is crucial. During supersolvus heat treatment, the primary $\gamma^{\prime}$ dissolves which leaves only the fine carbide, oxide and boride particles to provide Zener pinning to the grain boundaries and significant grain growth occurs. If $\gamma^{\prime}$ dissolution and $\gamma$ grain growth is not uniform and homogeneous there is a risk of developing a far coarser grain microstructure than intended. The presence of coarser grains will reduce the tensile strength of the material and also reduce fatigue strength as large favorably oriented grains can act as fatigue initiation sites [3].

In recent years it has been widely reported that inhomogeneous grain coarsening behavior is seen in many powder metallurgy nickel-based superalloys. The extent of grain coarsening appears to be primarily linked to the forging operations applied prior to solution heat treatment. The most commonly reported phenomenon is that of excessive grain growth due to high strain rate during forging. This is generally termed critical grain growth (CGG) as it refers to a critical strain rate window (depending on forging temperature) within which sudden, excessive grain growth occurs during supersolvus heat treatment. This has been observed for the P/M nickel alloys René 88 DT [4], LSHR [5] and N18 [6].

Using a matrix of double cone compression test specimens Huron et al. [4] have reported the forging conditions under which CGG occurs in René 88 DT. The propensity for CGG upon supersolvus heat treatment has been attributed to a specific strain rate range during forging. Under these conditions there is a low value of $\mathrm{m}$ (the strain rate sensitivity coefficient), which indicates limited superplastic behavior and hence the accumulation of dislocation density through deformation. Tu and Pollock [7] have assessed the deformation mechanisms during high temperature compression testing of René $88 \mathrm{DT}$. Above a critical level of strain rate between $0.0032 \mathrm{~s}^{-1}$ and $0.032 \mathrm{~s}^{-1}$ a transition from superplastic deformation with extensive grain boundary sliding to intergranular deformation and dynamic recrystallization was inferred from Electron Backscatter Diffraction (EBSD) characterization. At moderately low strain rates superplastic deformation enhanced 
grain growth was observed to increase the grain size compared to the as-extruded material. At high strain rates dynamic recrystallization was reported where local strain was as low as 0.1 , leading to grain refinement compared to the as-extruded material. Strain mapping techniques showed that plastic strain accumulates inhomogeneously in individual grains before dynamic recrystallization is initiated.

Semiatin et al. [8] have investigated the plastic flow behavior of LSHR alloy during isothermal hot compression below the $\gamma^{\prime}$ solvus temperature. Three behaviors depending on strain rate and temperature were noted. At low temperatures and high strain rates flow softening due to discontinuous dynamic recrystallization was observed. At higher temperatures and low strain rates superplastic steady-state flow indicative of grain/interphase boundary sliding and limited grain growth occurs. At temperatures just below the $\gamma^{\prime}$ solvus at low strain rates flow hardening associated with dynamic grain growth occurs and leads to irregular $\gamma$ grain and $\gamma^{\prime}$ microstructures and can lead to substantially coarser (but not "grossly abnormal") grain sizes during the subsequent supersolvus heat treatment.

Other investigations into excessive grain coarsening of René 88 DT have focused on a theory that upon supersolvus heat treatment of a microstructure containing inhomogeneous stored strain, discrete grains will have sufficient energy to overcome Zener pinning and begin growing before their nearest neighbors. Despite the plausibility of this hypothesis, extensive microstructural characterization, in particular by Whitis [9] and Payton [10], has found no definitive proof that increased levels of stored energy in the form of dislocation density are present in regions known to exhibit CGG upon supersolvus heat treatment. Work by Cho et al. [11] on room temperature strain and subsequent supersolvus heat treatment of René 88 describes a grain growth mechanism facilitated by the absorption of lattice dislocations at the grain boundaries, increasing their mobility.

A recent assessment of grain growth in Alloy 718 during $\delta$ subsolvus annealing [12] has described an excessive grain growth mechanism in regions of moderately low applied tensile strain, but not at high or very low applied strains. This window of low local forging strain was found to produce significantly coarser grains containing many twin boundaries and incoherent $\delta$ phase particles as a result of ineffective Zener pinning. Extensive EBSD characterization has been used to assess the relative misorientation and estimate the recrystallized volume fraction within the strained material. This experimental work has been used to develop a numerical model for strain induced selective grain growth.

The formation of twin and special boundaries has been assessed by Detrois et al. [13] in RR1000 compressed at different strain rates and temperatures to investigate the potential for grain boundary engineering. Particular focus in this study was on the volume fraction of coherent twin boundaries with $\Sigma=3$ which possess some of the lowest grain boundary energies. Samples compressed at low temperatures and high strain rates contained low length fraction of $\Sigma 3$ twin boundaries and high levels of intragranular misorientation in the as-compressed condition. However, after supersolvus heat treatment these samples contained the longest length of low mobility $\Sigma 3$ boundaries and very low levels of intra-granular misorientation, indicating that plastic strain energy contributes to the formation of $\Sigma 3$ twin boundaries.
The experimental work presented below describes a distinct inhomogeneous grain growth phenomenon which has been observed in supersolvus heat-treated RR1000. The dominant factor affecting this grain growth process appears to be the level of forging strain, rather than strain rate. The regions showing excessive grain coarsening are typically characterized by low (but not zero) forging strain and consistently low levels of forging strain rate. The process typically causes grain size to increase by a factor of two, but does not cause the dramatically bimodal grain structures seen as a consequence of CGG. To make this distinction it has been described here as an abnormal grain growth (AGG) phenomenon caused by the inhibited or premature growth of certain grains relative to their neighbors. However, it is recognized that there are likely to be similarities in the fundamental driving force for $\mathrm{AGG}$ and $\mathrm{CGG}$.

\section{Material and Experimental Procedures}

Extruded RR1000 billet material supplied by PCC Special Metals Corporation has been used throughout this work. The microstructure from the mid-radius region of this billet material is shown in Figure 1 which shows a fine $\gamma$ grain size (average of around $2.5 \mu \mathrm{m}$, ASTM 14) and a uniform distribution of fine primary $\gamma^{\prime}$ particles (around $28 \%$ area fraction).

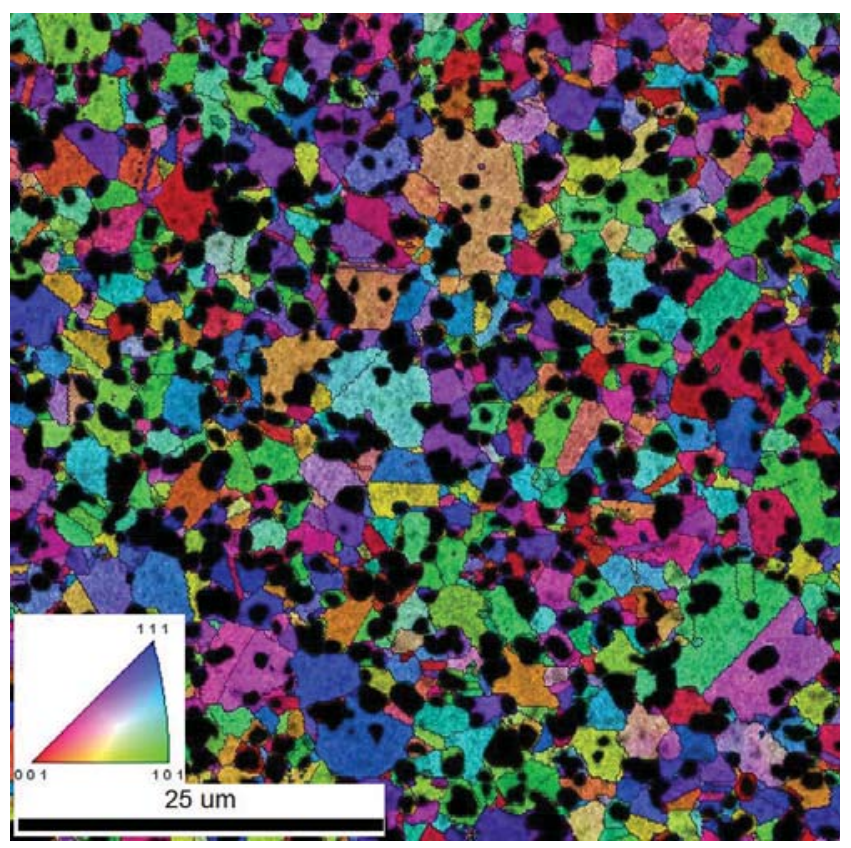

Figure 1. Microstructure from the mid-radius location of RR1000 billet material used in this work. EBSD Inverse Pole Figure (IPF) plus Grain Boundary map with primary $\gamma^{\prime}$ particles identified by an overlay of regions showing low chromium content under energy dispersive X-ray spectroscopy (EDX).

RR1000 billet material has been machined into right circular cylinder (RCC) compression specimens of diameter $9 \mathrm{~mm}$ and height $12 \mathrm{~mm}$ for the assessment of strain rate sensitivity. Constant die velocity compression testing has been carried out at a range of strain rates and temperatures.

RR1000 billet material has also been machined into small double cone (DC) compression specimens, shown in Figure 2. A matrix of compression tests conducted at a range of temperatures has 
been used to assess the effect of local variations in forging strain and strain rate on microstructural evolution. In order to replicate production procedures a 5 hour pre-soak at the required forging temperature was carried out in a laboratory furnace followed by an air cool. The DC specimens were then re-heated in the compression rig and held for 20 minutes before applying a constant strain rate until a $50 \%$ upset was achieved.

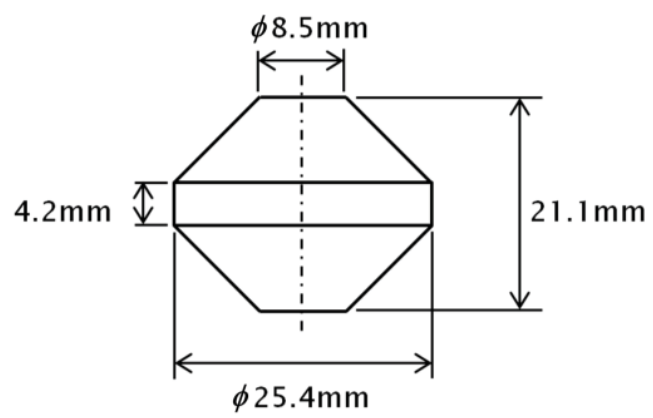

Figure 2. Double Cone (DC) specimen dimensions before compression.

In order to assess grain growth in material forged on a scale more representative of production components the center-slug portion from a full-scale HPT disc has been sourced from ATI Forged Products, Cudahy. An isothermal forging press was used to apply a strain rate of $0.003 \mathrm{~s}^{-1}\left(0.2 \mathrm{~min}^{-1}\right)$ at a temperature of $1099{ }^{\circ} \mathrm{C}$ $\left(2010^{\circ} \mathrm{F}\right)$ to PCC Special Metals Corporation billet material. The cylindrical center-slug from the middle of the disc was then machined out and delivered to Rolls-Royce plc in the as-forged condition. Although assessment of this material only covers one forging temperature and the strain rate is consistently low, a wide variation in forging strain has been applied along its length.

In all the work described efforts have been made to replicate full-scale production processes using small laboratory samples. The temperature profiles from forging and heat treatment that were required for this work are shown in Figure 3. A key aspect of this procedure has been to replicate the slow heating ramp rate profile that a large component would experience in a production furnace using a much smaller sample in a laboratory furnace. This work has found that grain coarsening occurs very rapidly during heating. Just below the $\gamma^{\prime}$ solvus temperature a critical point is reached where partial dissolution of the primary $\gamma^{\prime}$ particles has limited their effectiveness at pinning grain boundaries and it is energetically favorable for $\gamma$ grains to coarsen. It has been found that slower heating through this critical temperature range exacerbates the grain sizes produced by AGG.

Two heating profiles were used in this work: A '55 minute' heating profile, which approximately follows that of a medium sized production component, with a heating rate of $4{ }^{\circ} \mathrm{C}$ per minute at the critical point just below the $\gamma^{\prime}$ solvus temperature; and a slower '93 minute' heating profile with a heating rate of $1{ }^{\circ} \mathrm{C}$ per minute just below the $\gamma^{\prime}$ solvus temperature. These heating profiles can be seen in Figure 4. A 1 hour hold time at the supersolvus heat treatment temperature of $1170{ }^{\circ} \mathrm{C}$ was selected for this work as investigations into longer hold times were not found to cause any significant variation to the microstructure. In some cases the supersolvus heat treatment has been interrupted before reaching the hold temperature and samples have been removed to static air quench. This has enabled the investigation of microstructures present at the start of grain growth.
Grain boundary microstructures have been visualized by grinding with $\mathrm{SiC}$ paper up to 2500 grit, polishing with dilute $0.4 \mu \mathrm{m}$ colloidal silica and swab etching with waterless Kalling's reagent. More detailed microstructural characterization has been carried out using Scanning Electron Microscopy (SEM) and Electron Backscatter Diffraction (EBSD) techniques. Average grain sizes have been calculated using the lineal intercept grain size measurement procedure outlined in ASTM E112 [14]. As-LargeAs (ALA) grain sizes have been calculated by measuring the maximum caliper diameter and the diameter perpendicular to that of the largest visible grain in a cross sectioned sample to estimate the area as outlined in ASTM E930 [15].

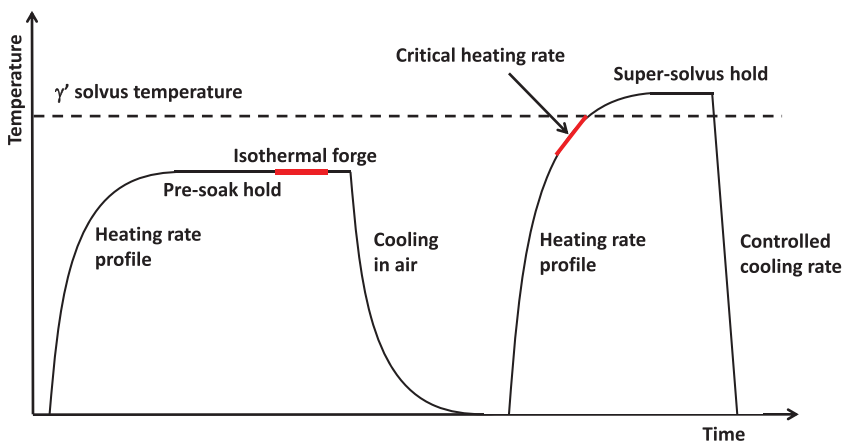

Figure 3. Schematic of forging and supersolvus heat treatment temperature profile relative to the $\gamma^{\prime}$ solvus temperature.

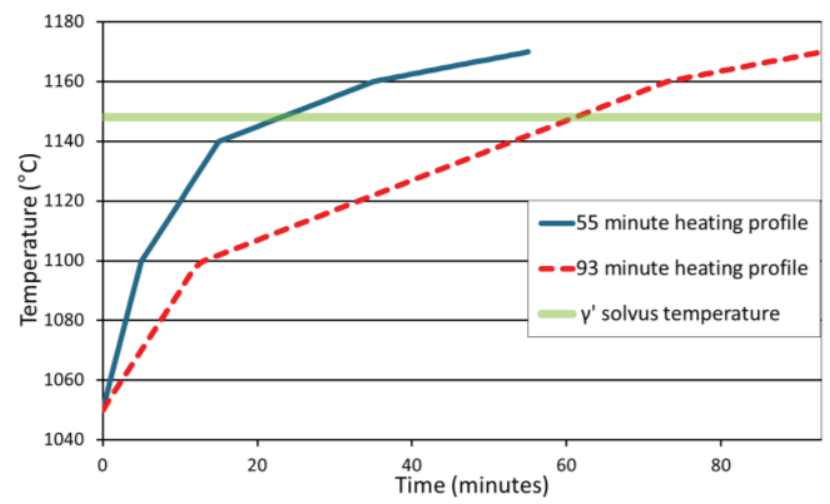

Figure 4. '55 minute' and '93 minute' heating profiles used for small samples in the laboratory in order to replicate the heating rate through the $\gamma^{\prime}$ solvus temperature experienced by a large component put into a furnace at $1170{ }^{\circ} \mathrm{C}$.

\section{$\underline{\text { Remnant Powder Features }}$}

Within the billet microstructure of RR1000 there typically exist a very low area fraction of anomalous grains visible by microstructural characterization. These appear to be remnants of the original powder particles as they are rounded, roughly the same size as the sieved powder and often elongated in the extrusion direction. EBSD analysis has indicated that these features are single large grains typically containing coherent $\gamma^{\prime}$ particles of around $500 \mu \mathrm{m}$ diameter (notably finer than typical primary $\gamma^{\prime}$ ) which in many cases appear aligned in rows. There appear to be more of these features present towards the rim of the extruded billet. It is not clear how these feature form, but they are likely to be un-recrystallized powder particles that have remained within the confines of the prior-particle boundary. 
Remnant powder features are also found in as-forged material. Figure 5 shows an Electron Backscatter Diffraction (EBSD) map and an Energy Dispersive X-Ray Spectroscopy (EDX) scan of chromium composition of two of these features found in an RCC compression specimen forged at $0.3 \mathrm{~s}^{-1}$ at $1075^{\circ} \mathrm{C}$. The EDX scan shows that the $\gamma^{\prime}$ sub-structure within these features is clearly different to the bulk material. The Inverse Pole Figure (IPF) EBSD map indicates that the features are single $\gamma$ grains and the slight variation in the crystallographic orientation within them is likely to be a consequence of the high area fraction of $\gamma^{\prime}$ precipitates. Although no direct evidence links these features to the initiation of grain growth, the potential influence of such an anomaly in the $\gamma / \gamma^{\prime}$ microstructure should not be overlooked.

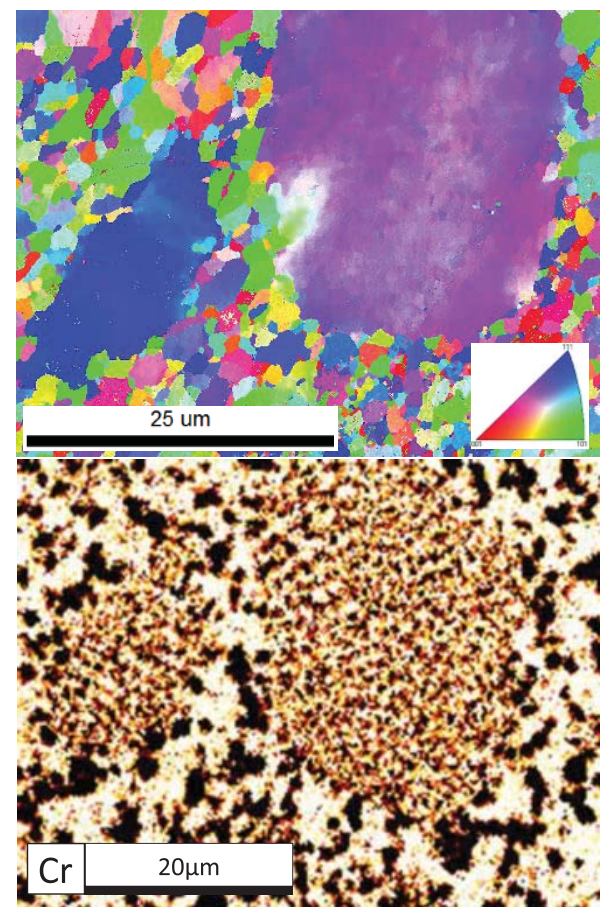

Figure 5. EBSD Inverse Pole Figure (IPF) map [top] and chromium composition EDX map (highlighting the $\gamma^{\prime}$ phase as black regions with an absence of chromium) [bottom] of remnant powder particle features found in a cross-sectioned RCC specimen compressed at $0.3 \mathrm{~s}^{-1}$ at $1075^{\circ} \mathrm{C}$. These features appear to be single grains containing coherent $\gamma^{\prime}$ of around $500 \mu \mathrm{m}$ diameter which are occasionally aligned in rows.

\section{Results}

\section{$\underline{\text { RCC compression Testing }}$}

Fitted flow stress plots for compression of the RCC specimens at a nominal strain rate of $0.003 \mathrm{~s}^{-1}$ at $1038^{\circ} \mathrm{C}, 1050{ }^{\circ} \mathrm{C}$ and $1099{ }^{\circ} \mathrm{C}$ are shown in Figure 6. Flow stresses at various higher nominal strain rates during compression at $1050{ }^{\circ} \mathrm{C}$ are shown in Figure 7. At higher strain rates flow softening characteristic of dynamic recrystallization occurs. At lower strain rates the stress-strain plots are steady state indicating that deformation is predominantly superplastic and strain is accommodated by grain boundary sliding rather than the build-up of dislocations [8]. The slight flow hardening seen in the lower strain rate plots is thought to be a consequence of constant die velocity as the effective strain rate is increasing during the compression stroke, rather than any strain hardening due to the build-up of dislocation density.

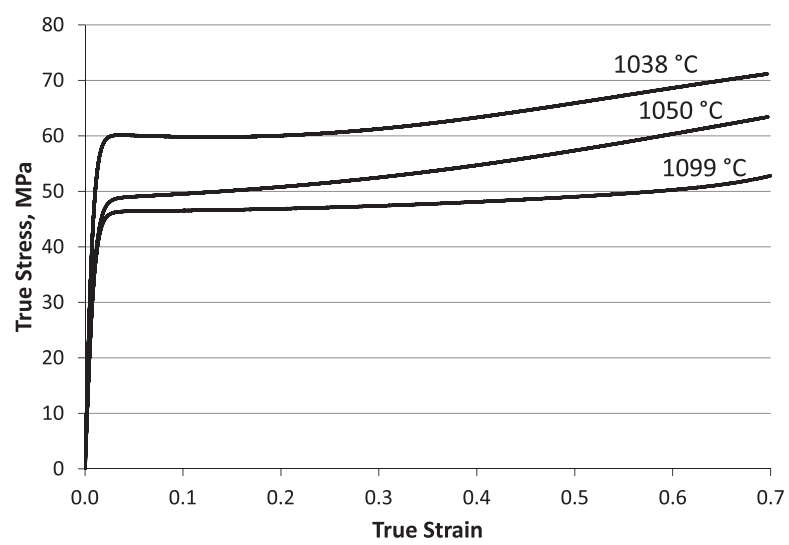

Figure 6. Right Circular Cylinder curve fitted flow stress data during nominally $0.003 \mathrm{~s}^{-1}$ compression at $1038^{\circ} \mathrm{C}, 1050{ }^{\circ} \mathrm{C}$ and $1099^{\circ} \mathrm{C}$. Note that constant die velocity was used in these tests.

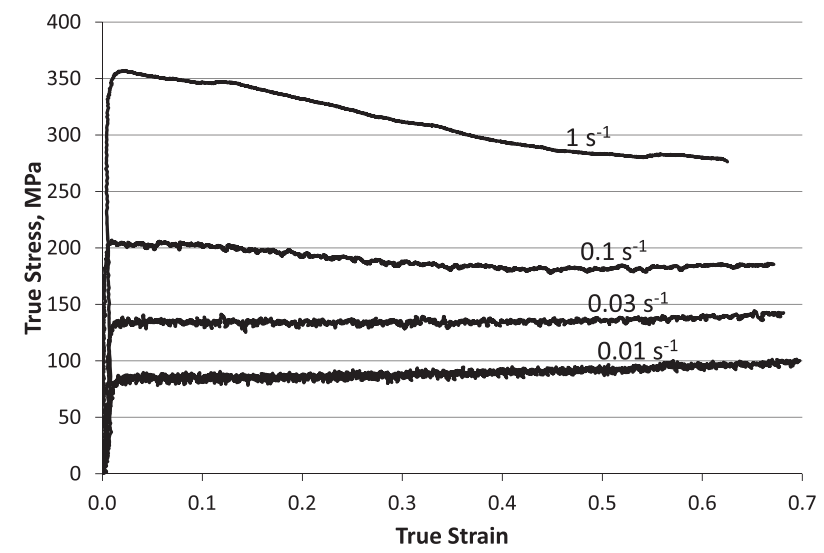

Figure 7. RCC flow stress data during compression at $1050{ }^{\circ} \mathrm{C}$ using nominal strain rates of $1 \mathrm{~s}^{-1}, 0.1 \mathrm{~s}^{-1}, 0.03 \mathrm{~s}^{-1}$ and $0.01 \mathrm{~s}^{-1}$. Note that constant die velocity was used in these tests.

\section{DC compression testing}

The forging strain model for the DC specimen after compression to a $50 \%$ upset is shown in Figures 8, with the expected forging strain at three locations of interest highlighted.

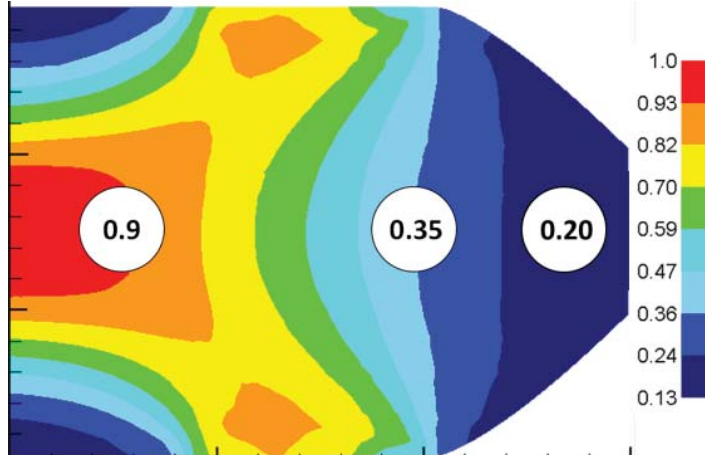

Figure 8. Final forging strain (unitless) model for the Double Cone (DC) samples after $50 \%$ upset using a constant strain rate. The final forging strain has been shown circled at the three locations of interest. 
(a)

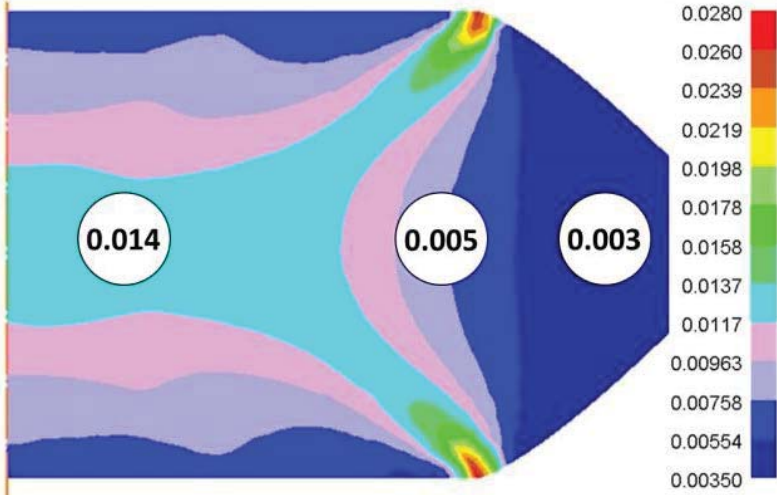

(b)
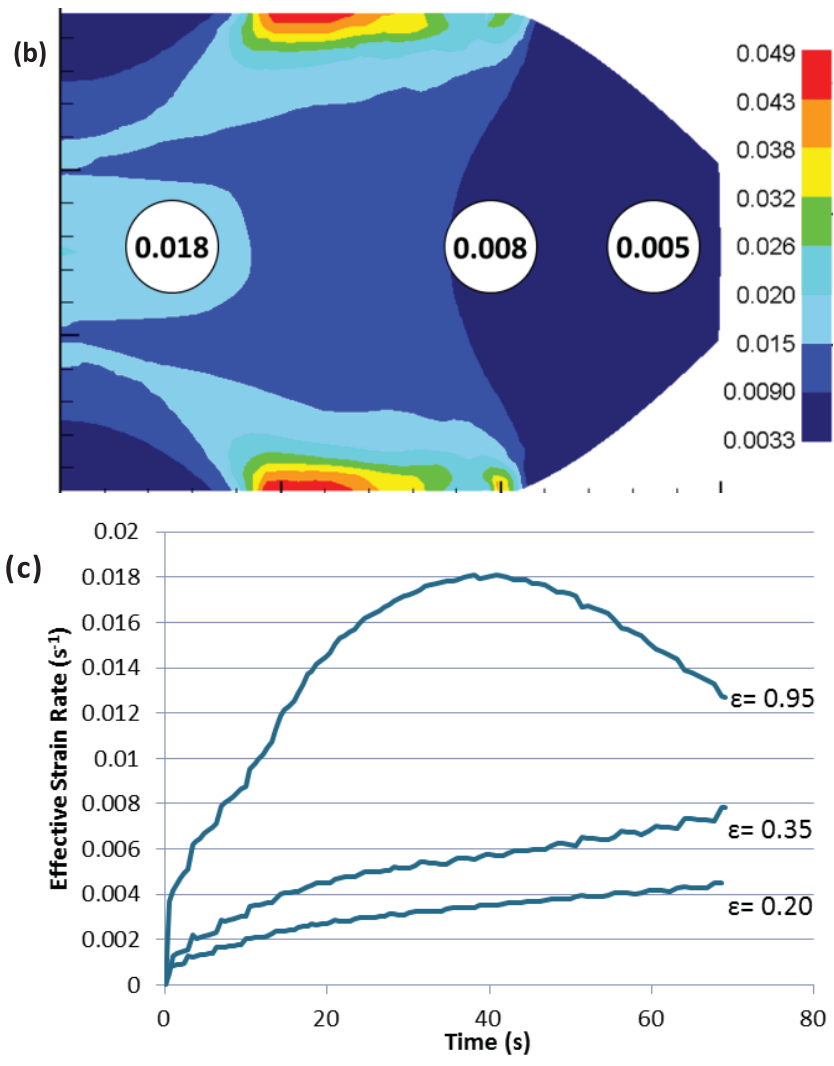

Figure 9. Average effective forging strain rate (a) and maximum instantaneous forging strain rate (b) models for the DC samples when using an applied nominal strain rate of $0.01 \mathrm{~s}^{-1}$ at $1110^{\circ} \mathrm{C}$. Values at the three locations of interest indicated in Figure 8 are shown circled. Plot (c) shows the variation in modelled effective strain rate vs. forging time for these three locations.

Figure 9 (a) shows the average forging strain rate model and Figure 9 (b) shows the maximum instantaneous strain rate model for a compression test carried out at $0.01 \mathrm{~s}^{-1}$ nominal applied strain rate at a temperature of $1110{ }^{\circ} \mathrm{C}$. The average and maximum instantaneous strain rates are indicated at the same three locations of interest. Figure 9 (c) shows the modelled strain rate at these three locations of interest plotted against forging time. DC compression tests modelled over the range of temperatures and strain rates assessed in this work show a similar effective strain rate vs. temperature profile relative to the nominal applied strain rate.

After compression the DC specimens have been cross-sectioned through the compression axis using a slow feed rate precision saw and the grain size in the three locations of interest has been measured. As-forged grain sizes were found to increase with increasing forging temperature, but no significant grain size variation was found between specimens forged at different strain rates or in regions of different forging strain. Table I shows the grain size in the 0.35 forging strain location at each of the compression temperature and strain rate conditions.

Table I. Average grain size in DC specimens after compression*.

\begin{tabular}{|c|c|c|c|c|c|c|c|c|c|}
\hline \multicolumn{2}{|c|}{ Avg. Grain Size } & \multicolumn{8}{|c|}{ Forging temperature $\left({ }^{\circ} \mathrm{C}\right)$} \\
\hline ASTM & $\mu \mathrm{m}$ & \multicolumn{2}{|c|}{1052} & \multicolumn{2}{|c|}{1077} & \multicolumn{2}{|c|}{1093} & \multicolumn{2}{|c|}{1110} \\
\hline \multirow{4}{*}{$\begin{array}{c}\text { Nominal } \\
\text { Strain } \\
\text { rate }\left(\mathrm{s}^{-1}\right)\end{array}$} & 0.003 & 13.7 & 3.1 & 13.5 & 3.3 & 12.9 & 4.1 & 12.7 & 4.4 \\
\hline & 0.01 & 13.4 & 3.5 & 13.7 & 3.1 & 12.9 & 4.1 & 12.7 & 4.4 \\
\hline & 0.03 & 13.4 & 3.5 & 13.3 & 3.6 & 13.6 & 3.2 & 12.9 & 4.1 \\
\hline & 0.3 & 14.1 & 2.7 & 13.5 & 3.3 & 13.2 & 3.7 & 12.6 & 4.6 \\
\hline
\end{tabular}

*All measurements taken from the 0.35 forging strain region using the ASTM lineal intercept average grain size measurements and converting to average grain diameter $\bar{d}$ in microns [14].

Further cross-sectioning of the as-compressed DC specimens was carried out to produce one-sixth sector slices. One slice from each forging strain rate and temperature condition was supersolvus heat treated in a laboratory furnace using the controlled ' 55 minute' heating profile and held at $1170{ }^{\circ} \mathrm{C}$ for one hour. A controlled cooling rate and subsequent aging heat treatment was used to coarsen the secondary and tertiary $\gamma^{\prime}$ particles respectively. This does not affect $\gamma$ grain size, but gives an improved grain boundary etch response.

Figure 10 shows micrographs of the full matrix of supersolvus heat treated DC compression specimens in the polished and waterless Kalling's reagent etched condition to highlight grain boundaries. Average ASTM grain size measurements at the three locations of differing forging strain indicated in Figure 8 are also shown. For clarity these data are repeated in Table II converted to average grain diameter in microns [14]. The extent of overall coarsening was accentuated in the DC specimens that had been forged at higher temperatures and lower nominal strain rates. Additionally, in these specimens there is a clear increase in supersolvus $\gamma$ grain size in the lower forging strain regions. This is thought to be the consequence of an abnormal grain growth process.

Despite the wide range of forging temperatures and strain rates examined by this compression test matrix, no gross CGG was seen in regions of high strain rate resembling the René 88 DT DC specimen microstructures presented by Huron et al. [4]. 


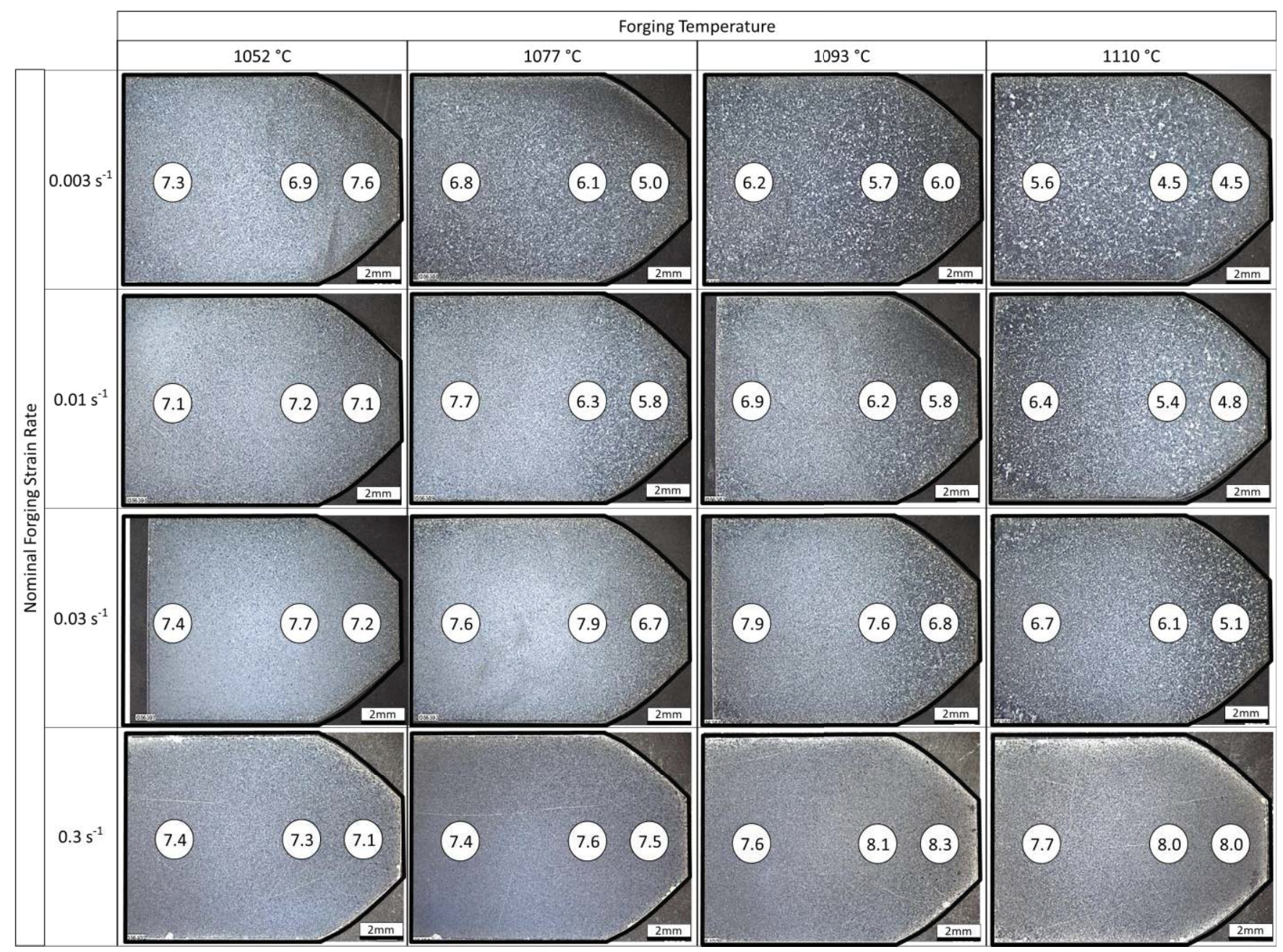

Figure 10. Average ASTM grain size values are shown, measured by the lineal intercept method, from the regions of $0.95,0.35$ and 0.2 forging strain in the DC specimens after supersolvus heat treatment in a laboratory furnace using the ' 55 minute' heating profile.

Table II. Tabulated grain sizes in the supersolvus heat treated DC specimens* expressed using average grain diameter $\bar{d}$ [14] in microns.

\begin{tabular}{|c|c|c|c|c|c|c|c|c|c|c|c|c|c|}
\hline \multirow{2}{*}{\multicolumn{2}{|c|}{$\begin{array}{r}\text { Forging Temp } \rightarrow \\
\text { Local strain level } \rightarrow\end{array}$}} & \multicolumn{3}{|c|}{$1052^{\circ} \mathrm{C}$} & \multicolumn{3}{|c|}{$1077^{\circ} \mathrm{C}$} & \multicolumn{3}{|c|}{$1093^{\circ} \mathrm{C}$} & \multicolumn{3}{|c|}{$1110^{\circ} \mathrm{C}$} \\
\hline & & 0.9 & 0.35 & 0.2 & 0.9 & 0.35 & 0.2 & 0.9 & 0.35 & 0.2 & 0.9 & 0.35 & 0.2 \\
\hline \multirow{4}{*}{$\begin{array}{c}\text { Nominal } \\
\text { Strain rate } \\
\left(\mathrm{s}^{-1}\right)\end{array}$} & 0.003 & 28.6 & 32.9 & 25.8 & 34.0 & 43.4 & 63.5 & 41.9 & 49.8 & 44.9 & 51.6 & 75.5 & 75.5 \\
\hline & 0.01 & 30.7 & 29.6 & 30.7 & 24.9 & 40.5 & 48.1 & 32.9 & 41.9 & 48.1 & 39.1 & 55.3 & 68.1 \\
\hline & 0.03 & 27.6 & 24.9 & 29.6 & 25.8 & 23.2 & 35.2 & 23.2 & 25.8 & 34.0 & 35.2 & 43.4 & 61.3 \\
\hline & 0.3 & 27.6 & 28.6 & 30.7 & 27.6 & 25.8 & 26.7 & 25.8 & 21.7 & 20.2 & 24.9 & 22.5 & 22.5 \\
\hline
\end{tabular}

*Replicating the data shown in Figure 10 for the three regions of interest with a local forging strain level of $0.9,0.35$ and 0.2 .

\section{Supersolvus heat treatment of material from a full-scale forging}

The as-forged center-slug removed from a full-scale HPT disc was selected to investigate the mechanism of AGG as it contained a gradual variation in local forging strain along its length and consistently low levels of effective strain rate. The component was forged at a nominal strain rate of $0.003 \mathrm{~s}^{-1}$ at $1099{ }^{\circ} \mathrm{C}$ $\left(2010^{\circ} \mathrm{F}\right)$. The $\mathrm{DC}$ compression specimen matrix indicates that at this high forging temperature and low applied strain rate, regions of low forging strain should experience AGG. An RCC compression test carried out under these same forging conditions indicates that the flow stress of the material is steady state, indicating fully superplastic grain boundary sliding behavior.
The center-slug material was cross-sectioned through the compression axis using a low feed rate precision saw such that thin slices were produced containing a gradual variation in applied forging strain (from near 0 at the bottom to around 1.8 at the top). Slices were then supersolvus heat treated in a laboratory furnace using both the ' 55 minute' and ' 93 minute' heating profile. A controlled cooling rate from the supersolvus hold temperature was used, but no subsequent aging heat treatment was applied. Figure 11 correlates the supersolvus heat treated average ASTM grain size as well as the ALA grain size against modelled forging strain variation along the length of these slices of material. In order to assess the effect of zero applied forging strain a sample of billet material taken from the mid-radius position was subjected to a 
temperature profile equivalent to the forging operation in a laboratory furnace followed by a supersolvus heat treatment with the '55 minute' heating profile.

It was found that in regions that had experienced moderately low (but not zero) forging strain a coarser average and ALA grain size was observed. The slower '93 minute' heating rate profile increased the average and ALA grain sizes in these locations up to a maximum of ASTM 4.4, ALA -0.5 at a local forging strain level of 0.8 .

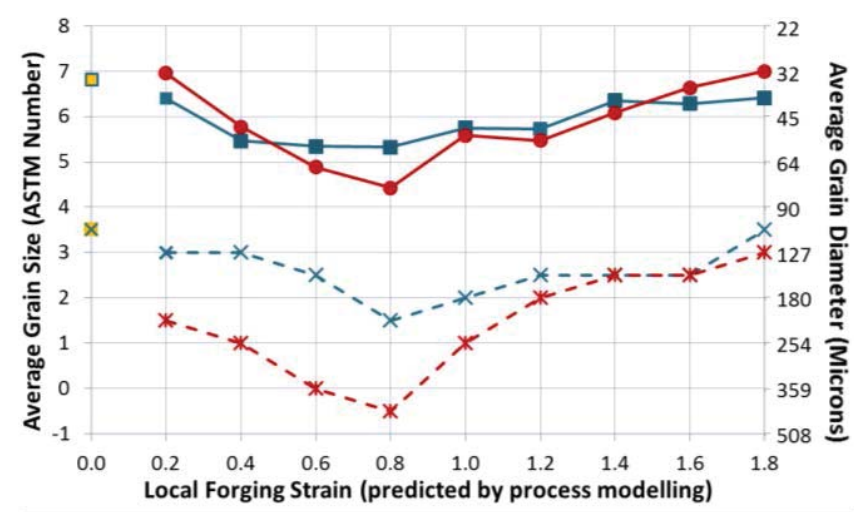

$\rightarrow-$ Average GS, 55 minute heating profile $\rightarrow$ Average GS, 93 minute heating profile $-\star$ ALA GS, 55 minute heating profile -* ALA GS, 93 minute heating profile - Average GS, zero strain forge HT + SSHT × ALA GS, zero strain forge HT + SSHT

Figure 11. Average ASTM lineal intercept grain size [14] and ASTM ALA grain size [15] measurements with corresponding average grain diameter $\bar{d}$ in microns plotted against local levels of forging strain predicted by modelling within the $1099{ }^{\circ} \mathrm{C}$, $0.003 \mathrm{~s}^{-1}$ forged center-slug material (see Figure 12).

The '55 minute' heating rate profile was repeated using another slice of material from the variable forging strain center-slug. However this time, once the sample had reached $1135-1140{ }^{\circ} \mathrm{C}$, it was removed to static air quench in an effort to retain the microstructure present whilst at temperature. These samples were polished and etched using a waterless Kalling's reagent to highlight the grain boundaries. Microstructural characterization found that the density of grains that had begun growing varied along its length. Figure 12 correlates micrographs of the interrupted heat treatment $\gamma$ grain microstructure with the level of local forging strain and maximum instantaneous strain rate predicted by process modelling of the center-slug forging conditions. In regions forged to $>1.4$ strain all visible grains had coarsened evenly, whereas in regions forged to $<0.8$ strain no coarsening was apparent. In the intermediate region between around 0.8 and 1.4 forging strain a bimodal microstructure of isolated coarsening grains surrounded by grains roughly the same size as in the as-forged microstructure was seen. In this intermediate region a clear increase in the area fraction of coarsening grains was found with increasing levels of forging strain.

This experiment was repeated, interrupting the '55 minute' heating profile at $1145-1150{ }^{\circ} \mathrm{C}$. The variation in grain sizes produced resembled those found the in the full ' 55 minute' heating profile supersolvus heat treatment carried out previously. No intermediate region of inhomogeneous grain growth initiation was present and it appeared that all visible grains had begun coarsening.

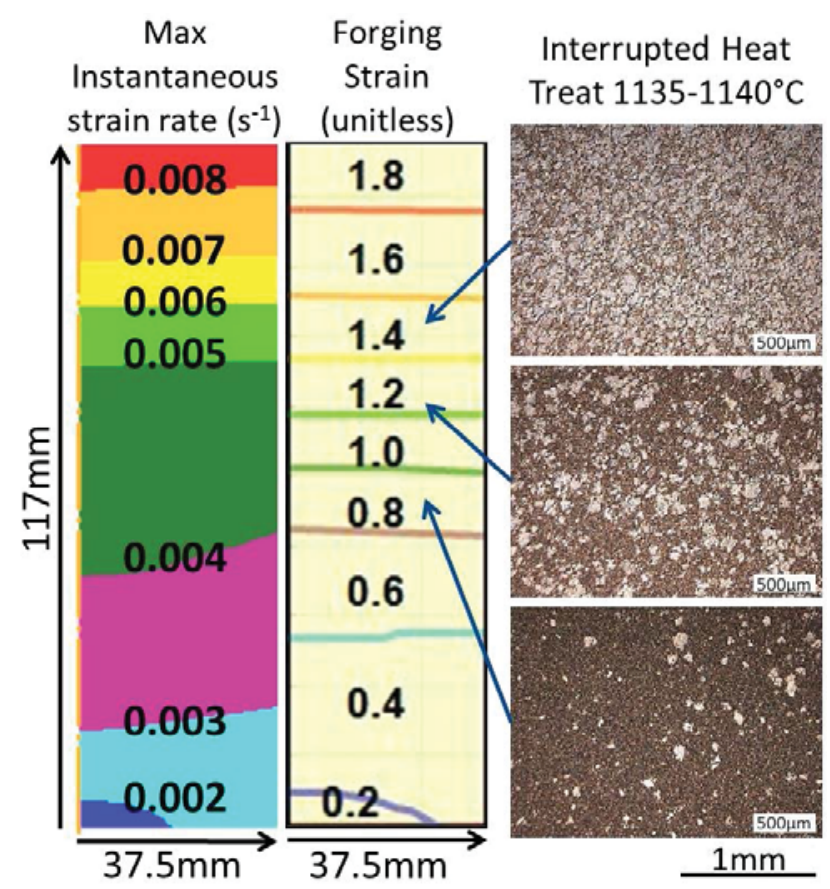

Figure 12. Forging strain model showing the variation in forging strain along the length of the $1099^{\circ} \mathrm{C}, 0.003 \mathrm{~s}^{-1}$ forged HPT disc center-slug material. Micrographs of a $0.8,1.2$ and 1.4 forging strain region after interrupting the ' 55 minute' heat treatment profile at $1135-1140{ }^{\circ} \mathrm{C}$ are also shown. A variation in the area fraction of coarsening grains is apparent in these optical microscope images; coarsened grains appear light and un-coarsened grains appear dark.

A number of $10 \mathrm{~mm}^{3}$ samples were taken from the 0.4 and 1.8 forging strain locations within the as-forged center-slug material. Detailed microstructural characterization in the as-forged condition was carried out using secondary electron microscopy (SEM) techniques. No obvious microstructural differences in asforged $\gamma$ grain size or $\gamma^{\prime}$ particle size or volume fraction were found between these two samples. Electron Back-scatter Diffraction (EBSD) has also been used to collect Grain Orientation Spread (GOS) maps from these samples; shown in Figure 13 with raw GOS data histograms shown below each map. The median grain misorientation in the 1.8 strain sample was around $0.35^{\circ}$, whereas it was slightly lower in the 0.4 strain sample at $0.25^{\circ}$. Some discrete grains of higher misorientation were identified in the areas scanned of both samples but a higher range of misorientation values was found in the 0.4 strain sample with some distinct outliers with a misorientation of $3.1^{\circ}$. An assessment of the length fraction of twin and special boundaries has found very little difference within the two maps shown; the 0.4 strain region contains $28 \% \Sigma 3$ twin boundaries whilst the 1.8 strain region contains $25 \% \Sigma 3$ twin boundaries. It should be noted that only a small region of each sample was scanned so this EBSD assessment and results may not be fully representative of the bulk.

Samples from the 0.4 strain and 1.8 strain locations were given an interrupted supersolvus heat treatment in a laboratory furnace. The ' 55 minute' heat treatment profile was interrupted at 1140 $1145^{\circ} \mathrm{C}$ and the samples were removed to static air quench. SEM characterization of both these samples in the as-polished condition using Back-Scattered Electron (BSE) mode to give high crystallographic grain contrast is shown in Figure 14. In the 0.4 
strain sample quenched at $1140-1145^{\circ} \mathrm{C}$ a clear bimodal $\gamma$ grain structure caused by inhomogeneous grain coarsening can be seen, whereas a homogeneously coarsening $\gamma$ grain structure is seen in the equivalent 1.8 strain sample. These have been compared to identical samples that have been heat treated following the full ' 55 minute' heating profile and supersolvus heat treatment. The final grain sizes produced by an inhomogeneous grain coarsening mechanism, as in the 0.4 strain sample, are notably coarser than those produced by a homogenous coarsening mechanism, as in the 1.8 strain sample.

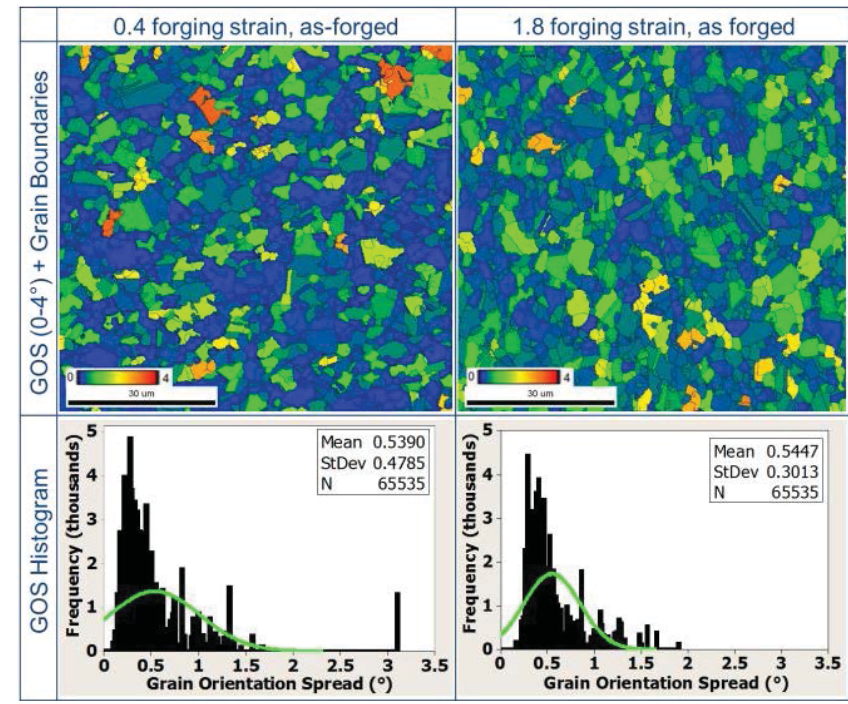

Figure 13. EBSD GOS (Grain Orientation Spread) maps and raw data histograms of the 0.4 strain and 1.8 strain regions of the center-slug material in the as-forged condition.

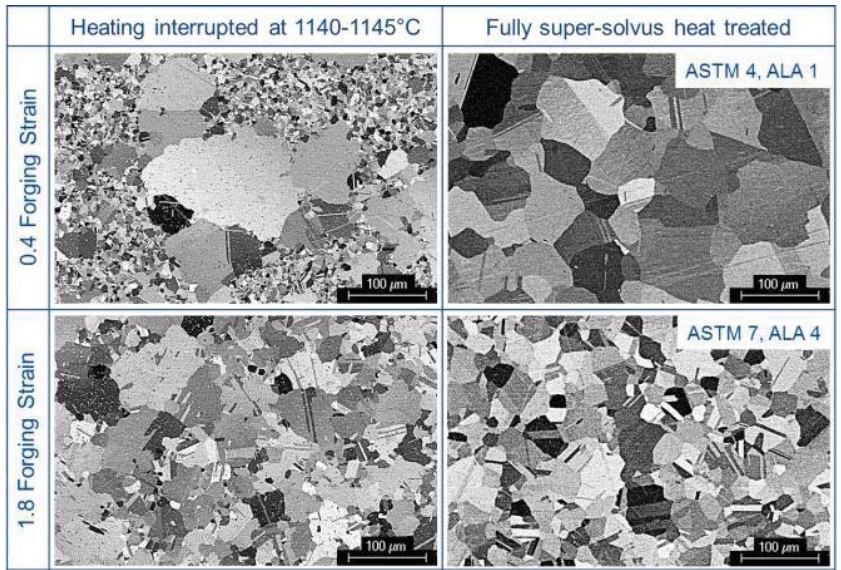

Figure 14. BSE SEM fractography of the 0.4 and 1.8 forging strain regions within the center-slug material after interrupted heat treatment at $1140-1145^{\circ} \mathrm{C}$ and after uninterrupted supersolvus heat treatment (following the ' 55 minute' heating profile) showing the relative difference in final average ASTM and ALA grain size.

The interrupted heat treatment 0.4 strain sample has been analyzed using combined EBSD and energy dispersive X-ray spectroscopy (EDX). Figure 15 shows an Inverse Pole Figure (IPF) map with a black overlay indicating the position of primary $\gamma^{\prime}$ particles (identified by regions of low chromium content in the EDX scan). These data have been used to identify the coherent and incoherent primary $\gamma^{\prime}$ particles within the bimodal $\gamma$ grain microstructure; where an incoherent particle is identified as being surrounded by a high angle grain boundary and containing low chromium content. Significant dissolution of the primary $\gamma^{\prime}$ particles has reduced them to around $4 \%$ area fraction. As these $\gamma^{\prime}$ particles reduce in size and the distance between them increases the Zener pinning force acting on the grain boundaries reduces. Despite the even distribution of $\gamma^{\prime}$ particles pinning particles which all show a consistent reduction in size, only discrete grains appear to have overcome the pinning force and begun growing in an unconstrained manner, passing through many primary $\gamma^{\prime}$ particles indicating that they have a high driving force to coarsen.

A KAM (Kernel Average Misorientation) map of the same area is also shown in Figure 15. The relative level of misorientation within some grains that appear to be coarsening is low compared to the bulk of non-coarsening grains, indicating that grain growth has reduced the level of stored strain energy. Notably however, the largest grain (bottom right of the map), which appears to have coarsened considerably as it contains many incoherent primary $\gamma^{\prime}$ particles, shows a relatively high level of intra-granular misorientation throughout. An assessment of low angle and special grain boundaries within the area analyzed shows significant twinning is present within the coarsened grains and the total length fraction of $\Sigma 3$ twin boundaries has increased relative to the as-forged samples to $36 \%$.

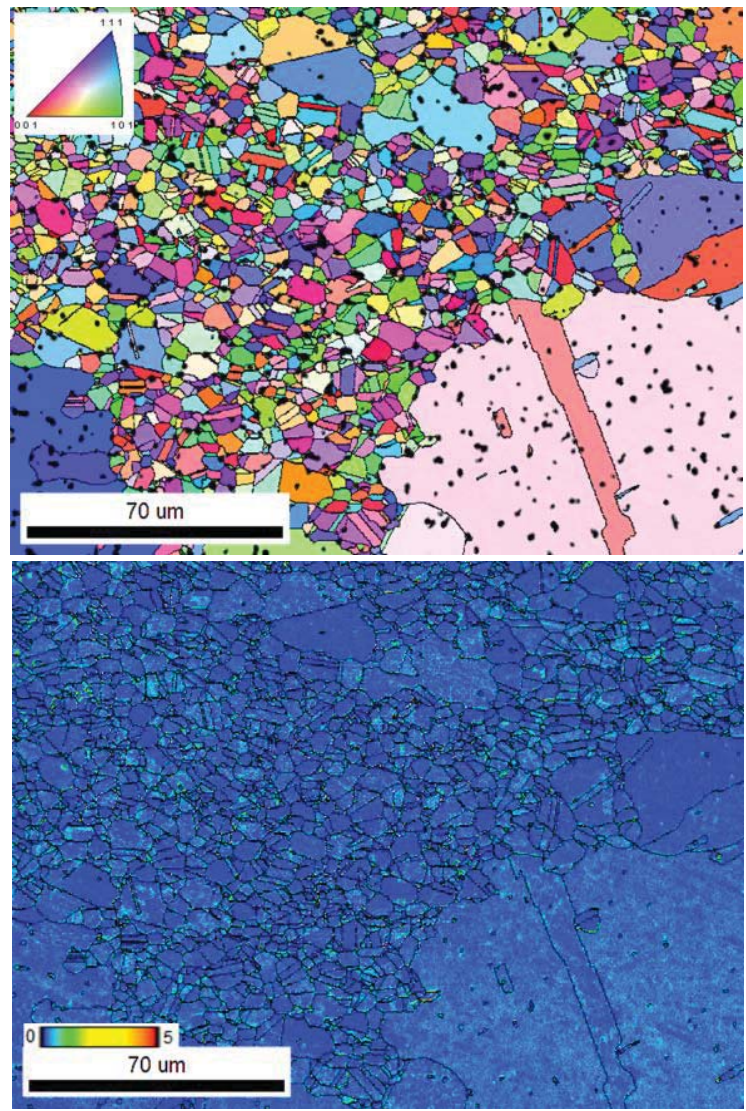

Figure 15 . EBSD maps of the 0.4 strain sample after $1140-1145^{\circ} \mathrm{C}$ interrupted heat treatment; [top] IPF (Inverse Pole Figure) with $>2{ }^{\circ}$ Grain Boundaries and an overlay of low $\mathrm{Cr}$ content positions shown in black to indicate the location of primary $\gamma^{\prime}$ particles and [bottom] a KAM (Kernel Average Misorientation) map with $>2{ }^{\circ}$ Grain Boundaries shown. 


\section{Discussion}

This experimental work has highlighted that the final grain size produced by supersolvus heat treatment of RR1000 is very sensitive to subtle variations in prior thermo-mechanical processing and in particular the local forging conditions. An extensive matrix of DC specimens has shown that coarser grains are found in supersolvus heat treated material that has been forged at higher sub-solvus temperatures and low strain rates, with the most excessive grain coarsening occurring in low strain regions. RCC specimen compression testing indicates that the flow stress under these forging conditions is steady-state, which is indicative of fully superplastic grain boundary sliding behavior.

Supersolvus heat treatments in a laboratory furnace using samples from the center-slug of a full-scale HPT disc component have also shown that slightly coarser grains are produced in regions of moderately low forging strain (indicated by process modelling). In addition it has been shown that reducing the heating rate through the $\gamma^{\prime}$ solvus temperature further increases the average and ALA grain sizes produced in moderately low forging strain regions.

Supersolvus heat treatments interrupted just below the $\gamma^{\prime}$ solvus temperature using material from the same HPT disc center-slug have shown that an inhomogeneous grain coarsening process occurs approaching the $\gamma^{\prime}$ solvus temperature. This behavior appears to be correlated with the window of moderately low applied forging strain which show excessively coarse grains in the fully supersolvus heat treated material. When samples were quenched at $1135-1140{ }^{\circ} \mathrm{C}$, it was found that in higher forging strain regions grain growth is initiated in a high number of grains whereas in lower forging strain regions very little evidence of grain coarsening was seen. This suggests that in higher strain regions there is a high density of grains with a high coarsening driving force and in low strain regions there is a generally low coarsening driving force. In the intermediate forging strain region the highly bimodal $\gamma$ grain microstructures which have been observed suggest that there exist discrete grains with a much higher coarsening driving force than their neighboring grains.

The inhomogeneous coarsening behavior observed in the interrupted supersolvus heat treatment samples indicate that as soon as the dissolution of the $\gamma^{\prime}$ pinning particles reaches a critical level those grains with the highest driving force will begin growing in an unconstrained manner and will end up dominating the microstructure. As a result of this process a coarser $\gamma$ grain microstructure is produced in moderately low forging strain regions than in either the higher forging strain or very low forging strain regions where a more homogeneous and competitive grain growth process occurs. Slowing the heating rate is likely to give more time for these discrete grains with a higher driving force to grow and dominate the microstructure before they are constrained by other growing grains.

The precise mechanism of the AGG phenomenon observed in this work is unclear. There does not appear to be any inhomogeneity in the as-forged microstructure or in the rate of dissolution of $\gamma^{\prime}$ pinning particles during heating to supersolvus temperatures. It is known that remnant powder features with an anomalous $\gamma / \gamma^{\prime}$ microstructure exist within the as-forged material, but given that they have not been seen in any significant density within the fullscale HPT disc center-slug material it is unlikely that they are directly causing the inhomogeneous grain growth initiation observed in this study.

This suggests that AGG in the moderate forging strain region must be driven by either an imbalance in stored strain energy or by discrete locations with higher grain boundary mobility. No obvious grain boundary or special boundary abnormalities have been observed in the crystallography of as-forged or interrupted heat treatment samples through EBSD mapping. It has however been shown that discrete grains containing slightly higher levels of crystallographic misorientation (often associated with stored work) are present in moderately low strain regions of as-forged samples. Compared to higher forging strain regions it was found that the bulk of the moderately low strain region contains low intra-granular misorientation, meaning that these discrete grains may contain significantly higher stored work than their nearest neighbors (see Figure 13). However, the absolute values of misorientation measured are very low and no direct link between grains with relatively high misorientation and early initiation of grain growth has been proven. Additional experimental work in the same vein as Tu and Pollock on René 88 DT [7] is required to further investigate strain accumulation and storage mechanisms over a range of applied strain and strain rates and the subsequent microstructural and crystallographic inhomogeneity produced.

The RCC compression tests indicate that strain rate sensitivity does decrease notably at high applied strain rates and deformation moves away from the superplastic regime. Work by Huron et al. [4] on René 88 DT has stated that regions with low strain rate sensitivity exhibited CGG as they were not fully superplastic. It is therefore unclear why no CGG was observed at high strain rates in this work, despite the range of nominal strain rates and temperatures assessed in the DC specimen test matrix.

Clearly grain growth phenomena are affected by the subtle balance of many factors, so it is vital to understand the safe processing window within which consistent and reliable components can be produced. As a result of this study an optimized forging window has been defined to avoid AGG upon supersolvus heat treatment of RR1000 alloy. For full-scale components it was found to be impractical to increase the supersolvus heat treatment heating rate as that is determined by the component size. It has been found that lower forging temperatures and higher applied forging strain rates can be implemented to produce a finer grain size in moderately low forging strain regions, as well as reducing grain size variability between regions of different forging strain.

\section{Summary and Conclusions}

RR1000 billet material has been forged using a wide range of isothermal forging temperatures and applied strain rates. Regions of differing forging strain level have been microstructurally characterized before and after supersolvus heat treatment using a slow heating rate through the $\gamma^{\prime}$ solvus temperature. An inhomogeneous grain growth initiation phenomenon leading to excessive coarsening of the microstructure has been observed in regions of moderately low, but not zero, forging strain. This has been described as an AGG process. Final grain sizes in lower strain regions were roughly twice the diameter of those in higher strain regions, but no gross coarsening often associated with the CGG phenomenon was apparent. 
Interrupted supersolvus heat treatments of low forging strain samples have shown that as the primary $\gamma^{\prime}$ particles dissolve and reduce in size, discrete grains are able to overcome the grain boundary Zener pinning force before their nearest neighbors and begin growing in an unconstrained manner. The experimental results described indicate that in low forging strain regions an imbalance in the levels of stored strain energy exists within the $\gamma$ grain microstructure and facilitates AGG upon slow heating to the supersolvus heat treatment temperature. An assessment of the level of crystallographic misorientation within regions of low and high forging strain samples provides some evidence that a higher range of intra-granular misorientation is present in low strain samples which exhibit AGG. However, further work should be carried out to investigate sources of inhomogeneity in the as-forged microstructure and link them directly to the inhomogeneous grain coarsening process during supersolvus heat treatment.

Although the exact mechanism by which this AGG process is initiated has not been identified, using a large matrix of DC compression specimens a clear forging process window for the occurrence of AGG in supersolvus heat treated RR1000 has been defined. The use of lower forging temperatures, higher applied strain rates or if possible faster heating rates to the supersolvus heat treatment temperature have been shown to avoid the occurrence of excessively coarse grains in low strain regions of isothermal forgings.

\section{Acknowledgements}

Thanks goes to PCC Special Metals Corporation for supplying RR1000 billet material, Swansea Materials \& Research Testing Ltd and the Advanced Forming Research Centre for use of their compression testing facilities, as well as Dr G. D. West of the Loughborough Materials Characterisation Centre and Dr Z. W. Huang and R.G. Ding of the University of Birmingham for use of their EBSD facilities.

\section{References}

1. D. M. Collins et al., "Grain Growth Behavior During Near $\gamma^{\prime}$ Solvus Thermal Exposures in a Polycrystalline Nickel-Base Superalloy," Acta Materialia, 61 (2013), 3378-3391.

2. R. J. Mitchell et al., "Process Development and Microstructure and Mechanical Property Evaluation of a Dual Microstructure Heat Treated Advanced Nickel Disc Alloy," Superalloys 2008, ed. R. C. Reed et al. (Warrendale, PA: The Minerals, Metals and Materials Society, 2008), 347-356.

3. T. P. Gabb et al., "Fatigue Resistance of the Grain Size Transition Zone in a Dual Microstructure Superalloy Disk," International Journal of Fatigue, 33 (2011), 414-426.

4. E. Huron, S. Srivatsa, E. Raymond, "Control of Grain Size via Forging Strain Rate Limits for René 88 DT," Superalloys 2000, ed. T. M. Pollock et al. (Warrendale, PA: The Minerals, Metals and Materials Society, 2000), 49-58.

5. T. P. Gabb et al., "Forging of Advance Disk Alloy LSHR," (Report NASA/TM - 213649, NASA Glenn Research Center, 2005).
6. M. Soucail, M. Marty, H. Octor, "The Effect of High Temperature Deformation on Grain Growth in a PM Nickel Base Superalloy," Superalloys 1996, ed. R. D. Kissinger et al. (Warrendale, PA: The Minerals, Metals and Materials Society, 1996), 663-666.

7. W. J. Tu, T. M. Pollock, "Deformation and Strain Storage Mechanisms During High-Temperature Compression of a Powder Metallurgy Nickel-Base Superalloy," Metallurgical and Materials Transactions A, 41A (2010), 2002-2009.

8. S. L. Semiatin et al., "The Effect of Forging Variables on the Supersolvus Heat-Treatment Response of Powder Metallurgy Nickel-Base Superalloys," Metallurgical and Materials Transactions A, 45A (2014), 6231-6251.

9. D. D. Whitis, "Recovery and Recrystallization after Critical Strain in the Nickel-Based Superalloy René 88 DT," Superalloys 2004, ed. K. A. Green et al. (Warrendale, PA: The Minerals, Metals and Materials Society, 2004), 391-400.

10. E. J. Payton, "Characterization and Modelling of Grain Boundary Coarsening in Powder Metallurgical Nickel-Based Superalloys," (Ph.D. thesis, The Ohio State University, 2009), 282-331.

11. Y. K. Cho, D. Y. Yoon, M. F. Henry, "The Effects of Deformation and Pre-Heat-Treatment on Abnormal Grain Growth in RENÉ 88 Superalloy," Metallurgical and Materials Transactions A, 32A (2001), 3077-3090.

12. A. Agnoli et al., "Selective Growth of Low Stored Energy Grains During $\delta$ Sub-solvus Annealing in the Inconel 718 NickelBased Superalloy," Metallurgical and Materials Transactions A, 46A (2015), 4405-4421.

13. M. Detrois et al., "Grain Boundary Engineering of PowderProcessed Ni-Base Superalloy RR1000: Influence of the Deformation Parameters," Materials Science and Engineering A, 627 (2015), 95-105.

14. ASTM International, ASTM E112-10, "Standard Test Method for Determining Average Grain Size," (ASTM International, West Conshohocken, PA, 2010).

15. ASTM International, ASTM E930-99, "Standard Test Method for Estimating the Largest Grain Observed in a Metallographic Section (ALA Grain Size)," (ASTM International, West Conshohocken, PA, 2007). 